\title{
Pós-graduação e pesquisa em educação no Brasil: o protagonismo da ANPEd
}

\author{
Sandra Zákia Sousa \\ Universidade de São Paulo, Programa de Pós-Graduação em Educação
}

\section{Lucídio Bianchetti}

Universidade Federal de Santa Catarina, Programa de Pós-Graduação em Educação

A ANPEd é um grande espaço de diálogo.

Alceu Ferraro

Concebo a ANPEd como um fórum de pensadores, um fórum de pensadores críticos, um fórum de pensadores críticos sensiveis.

Bernardete Gatti

\section{Introdução: metodologia de construção do texto}

Este é um texto urdido a muitas vozes, escrito a diversas mãos, plasmado na e pela vivência de vários anpedianos que se organizaram na Associação Nacional de Pós-Graduação e Pesquisa em Educação (ANPEd), animados pela crença de construir uma entidade que representasse qualificadamente os interesses das instituições e dos pesquisadores e servisse de mediação no interior da área de educação, entre as áreas e na representação ante os órgãos da sociedade civil e as agências governamentais.
É um texto que amplifica vozes, resgata e ressalta relatos, e tira da condição de silenciados fatos, aspectos e situações determinantes para aquilo que é e faz hoje a ANPEd. Pessoas que se reuniram, discutiram e tomaram posições movidas pela expectativa de que a associação assuma cada vez mais o protagonismo e a qualificada representação da área, interferindo na constituição e nos rumos da pós-graduação e da pesquisa em educação no Brasil.

Os que se reuniram para discutir e sistematizar aspectos marcantes dessa trajetória ${ }^{1}$ estavam cientes

\footnotetext{
${ }^{1}$ Como será detalhado a seguir, este texto resulta do debate
} realizado na Fundação Carlos Chagas (FCC), em São Paulo, nos dias 7 e 8 de maio de 2007. Participaram: Alceu Ravanello Ferraro (Centro Universitário La Salle - UNILASSALE-RS), Bernardete Angelina Gatti (FCC-SP e Pontifícia Universidade Católica de São Paulo - PUC-SP), Carlos Roberto Jamil Cury (PUC-MG), Jacques Therrien (Universidade Federal do Ceará - UFC), Maria Malta Campos (FCC e PUC-SP). O debate foi coordenado por Sandra Zákia Sousa (Universidade de São Paulo - USP) e Lucídio Bianchetti (Universidade Federal de Santa Catarina - UFSC), com 
do desafio, e da pretensão até, de enquadrar 30 anos de história e sintetizar 12 horas de discussão em poucas páginas. Muitos foram os pontos suscitados no debate, cujo teor explicita a riqueza que emana do nódulo denso de questões teóricas e práticas, do contraditório que constituiu a história da ANPEd. É um extenso leque de aspectos que evidencia o desencadeamento de uma práxis na qual se mesclam protagonismos de pessoas e do coletivo da associação, que se fizeram e se fazem presentes em momentos marcantes da história da pós-graduação em educação - interferindo inclusive na discussão e elaboração dos planos nacionais de pós-graduação e nos movimentos por uma educação de qualidade, pela redemocratização, nas discussões da Constituinte, nos embates no processo de elaboração da Lei de Diretrizes e Bases da Educação Nacional, do Plano Nacional de Educação e das Diretrizes Curriculares Nacionais, assim como na indicação de pesquisadores para ocupar postos de destaque na elaboração e implementação de políticas, no processo de indicação de membros para o Conselho Nacional de Educação (CNE) e na relação com outras entidades congêneres, entre outros aspectos.

Poder contar, no debate e na escrita coletiva deste texto, com colegas anpedianos históricos que protagonizaram essa história é uma vantagem. Concomitantemente, porém, exige vigilância maior, uma vez que podem facilmente se avolumar dificuldades na distinção entre realização, desejo ou crença, aspectos que interferem em análises históricas e prospectivas, e até mesmo as obnubilizam. Isso ajuda a entender por que os participantes estavam previamente cientes de que pretender resgatar a história, analisar o momento presente e prospectar o futuro em relação à ANPEd é, conforme explicitado por Cambi (1999, p. 38), "tratar de vias interrompidas, de possibilida-

a assessoria de Valéria Lopes (USP). Ficam aqui registrados, em nome da ANPEd e da Comissão Editorial da Revista Brasileira de Educação, os agradecimentos pela disponibilidade e pela colaboração desses colegas. des bloqueadas, de itinerários desprezados que devem ser compreendidos e afirmados e indicados como alternativas possíveis não só do passado, mas também do presente, pelo menos como alternativas teóricas, percursos diferentes, integradores e corretores de um modelo".

A partir do momento em que se decidiu que os 30 anos da ANPEd, além de merecerem espaço central na preparação e realização da $30^{\mathrm{a}}$ Reunião Anual, seriam contemplados com textos neste número da Revista Brasileira de Educação, passaram a ser feitas solicitações de artigos e procurou-se organizar um debate entre sócios da ANPEd que tiveram, direta ou indiretamente, atuação destacada na organização e nos rumos da associação. ${ }^{2}$

Nos dias 7 e 8 de maio de 2007 aconteceu a reunião, na FCC, em São Paulo. Os participantes elaboraram textos prévios, que serviram de base para o debate, que foi gravado e transcrito. Assim, o presente artigo origina-se do resgate da inserção de cada um desses participantes na história da associação, dos escritos prévios e de conteúdos extraídos do debate.

Pode-se dizer, servindo-se de um argumento bem conhecido, que esse foi um momento do método de investigação no qual lembranças se imbricaram com as análises. Nesse sentido, foram apontadas falas, fizeram-se remissões a textos, lembrou-se do sentido de muitas reuniões, e assim por diante. $\mathrm{O}$ desafio está em evitar tanto a dispersão, na qual se perderia a busca de significados mais amplos, como também uma teleologia prévia inscrita nesses 30 anos, que conduzisse a uma finalidade dada de antemão.

Para a construção deste texto, elencamos alguns temas extensamente debatidos, estruturados nos seguintes eixos: retrospectiva da criação e atuação da

${ }^{2}$ Da parte do professor Bruno Pucci contou-se com texto elaborado inicialmente a pedido da coordenação do Fórum Nacional dos Coordenadores de Programas de Pós-Graduação em Educação (FORPRED), fazendo um resgate da constituição e atuação do fórum. Nilton Fischer assumiu a responsabilidade de elaborar artigo focalizando a constituição e a atuação do Comitê Científico. 
ANPEd; cenário da educação nos tempos atuais; vicissitudes e desafios para a pesquisa em educação e a pós-graduação no Brasil. No debate, esses eixos foram sendo desdobrados, ganhando destaque as seguintes temáticas: criação da ANPEd, constituição e expansão dos programas de pós-graduação em educação; relação pós-graduação, pesquisa e formação; dinâmica interna de funcionamento da associação e relacionamento com instâncias do governo, grupos da sociedade civil e outras associações; indicação de possibilidades de consolidação ou ampliação de iniciativas da ANPEd.

\section{Criação induzida da ANPEd $x$ construção da autonomia}

Houve convergência entre os participantes no sentido da história da ANPEd, do ponto de vista da sua origem institucional, ${ }^{3}$ estar marcada pelas atitudes, discussões, embates, conflitos e decisões daqueles que estiveram envolvidos particularmente nas reuniões que marcaram sua criação e estruturação. As reuniões principais foram realizadas no Instituto de Estudos Avançados em Educação, da Fundação Getúlio Vargas (IESAE-FGV), no Rio de Janeiro, em 1976, e na Universidade Federal do Paraná, em Curitiba, em 1978, ambas convocadas e financiadas pela Coordenação de Aperfeiçoamento de Pessoal de Nível Superior (CAPES), quando foram discutidos e aprovados os estatutos da associação. ${ }^{4}$ Seguiram-se a

${ }^{3}$ É interessante ressaltar que, do ponto de vista da CAPES, propôs-se a criação da Associação Nacional de Cursos de PósGraduação em Educação. Ao ser criada a ANPEd denominou-se: Associação Nacional de Pós-Graduação em Educação (Carvalho, 2001). A inserção do termo "pesquisa" foi feita em 1981, por ocasião da primeira reforma do estatuto da ANPEd, na $4^{\mathrm{a}}$ Reunião Anual, realizada em Belo Horizonte, quando foi decidida também a criação dos grupos de trabalho.

${ }^{4}$ Isto pode ser verificado também nas entrevistas concedidas respectivamente a Fávero e Bianchetti (2005) e a Bianchetti (2005) por duas colegas que participaram dessas reuniões: Julieta Calazans e Juracy Marques. $1^{a}$ Reunião Anual (Fortaleza, 1978), na qual se discutiu a concepção do mestrado em educação no Brasil, com a participação dos coordenadores dos mestrados e doutorados existentes, e a $2^{\text {a }}$ Reunião Anual (São Paulo, 1979), na qual foi feita uma primeira abordagem sobre o doutorado em educação.

A ANPEd e outras associações científicas que foram criadas na década de 1970:

[...] surgiram ou foram induzidas para serem braços do Estado e, no encaminhamento dessa proposta, não se discutiu se a pesquisa tinha de anteceder a pós-graduação ou se a pós-graduação é que produziria condições de pesquisa. A idéia era a de desencadear uma pós-graduação em todas as áreas onde a pesquisa fosse precária ou extremamente limitada. E na área de humanas, especialmente na educação, isso era ainda mais acentuado. (Alceu Ferraro) ${ }^{5}$

Confirmando essa opção por parte dos órgãos governamentais, Saviani (2006, p. 143) ressalta:

Uma das estratégias acionadas pela CAPES, tendo em vista esse objetivo de consolidar a pós-graduação no país, foi induzir à criação de associações nacionais por área de conhecimento. Em decorrência das gestões então realizadas, surgiu na área de educação a Associação Nacional de Pesquisa e Pós-Graduação (ANPEd), que realizou sua primeira reunião anual em 1978, em Fortaleza.

Diz Alceu Ferraro: "Olho a criação da ANPEd como um projeto de pós-graduação vindo de cima para baixo, do governo militar". E desse projeto verticalizado decorreram inversões, ${ }^{6}$ como a confusão

${ }^{5}$ Algumas citações literais de fragmentos de falas dos participantes do debate aparecerão entre aspas. Suas citações e de outros autores serão mantidas destacadas, com indicação do respectivo autor.

${ }^{6}$ Embora os participantes do debate tenham convergido com essa questão da verticalização, foram feitas ressalvas ou restrições no sentido de que não seria possível generalizar. Cury, particularmente, afirma: “A dissertação de Nicolato (1986) demonstra 
de prioridade entre pós-graduação e pesquisa. E complementa:

O que vem primeiro: a pós-graduação gera a pesquisa ou o inverso? Não se decidiu, mas colocou-se a carreta na frente dos bois. No início da ANPEd a priorização era a pós-graduação. O primado não estava com a pesquisa. A pesquisa poderia até decorrer do ensino, mas a área era pobre em pesquisa. Isso predominou até o final da década de 1980.

No entanto, do ponto de vista político uma série de posturas e iniciativas da ANPEd rejeitou o modelo e postulava ser a associação apenas um preposto da CAPES e do Conselho Nacional de Desenvolvimento Científico e Tecnológico (CNPq), na execução das políticas e das atividades que os representantes dos órgãos governamentais desejavam. O passo inaugural de afirmação de um espaço de autonomia foi dado na eleição da primeira diretoria, conforme explicitado por Ferraro (2005) e nas entrevistas concedidas por Juracy C. Marques (Bianchetti, 2005) e Calazans (Bianchetti \& Fávero, 2005) e reproduzidas na Revista Brasileira de Educação n. 30. O teor desses depoimentos é confirmado pelo texto de Carvalho (2001), cujo significativo título é: "Origens da ANPEd: de instituída a instituinte".

Aliando-se à afirmação de que é necessário relativizar a compreensão de que no período somente aconteceram restrições, imposições, Maria Malta ressalta:

Não vejo tão negativamente assim. Na realidade, a consolidação da pós-graduação e da pesquisa no Brasil foi fortalecida naquele projeto do regime militar de "Brasil Grande". Era um projeto nacionalista, que partia da necessidade de o país adquirir uma autonomia em ciência e tec-

como a maioria das iniciativas já vinha sendo tomada pelo Conselho Federal de Educação (CFE) em clima de grande disputa. É certo que a resposta militar foi autoritária e verticalizada, e o Decreto-lei n. 477/69 faz parte desse contexto". Apesar dos comandos autoritários, contudo, resultados inesperados começaram a aparecer, como pode ser verificado na obra de Oliveira (1980). nologia. Era autoritário? Claro. Mas tinha esse aspecto nacionalista, e penso que por isso obteve apoio de grupos que representavam os cientistas. Por certo, as áreas de humanas eram mais hostilizadas pelos militares, mas ainda assim foram incluídas. Acho que houve um certo compromisso de parte a parte. É lógico que o grosso das verbas foi para as áreas duras e ligadas aos grandes projetos de infra-estrutura. Outra coisa a se lembrar é que, na passagem para a década de 1980, quando começava a "transição lenta e gradual", tivemos as grandes greves do $\mathrm{ABC}$, a eclosão dos movimentos sociais urbanos etc. Foi nesse contexto que os pesquisadores começaram a colocar as mangas de fora e a aproveitar os pequenos espaços de participação que se abriam. Isso não ocorreu no auge da violência militar, mas um pouco depois, não foi? As grandes reuniões da SBPC [Sociedade Brasileira para o Progresso da Ciência], por exemplo, foram nesse período, entre 1975 e 1985, segundo me lembro.

Vai ficando evidente, assim, que a ANPEd respondeu de um modo próprio a essa iniciativa de indução por parte do governo federal: além de admitir sócios institucionais (os programas de pós-graduação), abriu espaço para o ingresso de sócios individuais (docentes-pesquisadores e pós-graduandos).

Do ponto de vista político-pedagógico, muitas transgressões e até confrontos evidenciam essa relação conflituosa. Por exemplo, uma das primeiras comissões de avaliação negou-se a atribuir conceitos aos cursos, por considerar que acabariam prejudicando a área de educação. ${ }^{7}$ Evidentemente isso ocorreu em um momento em que a avaliação e o fomento não estavam tão intimamente imbricados, como veio ocorrendo e afirmando-se posteriormente, a ponto de hoje ser a avaliação que conforma o financiamento.

${ }^{7}$ De acordo com Fávero (1999, p. 8), houve uma "recusa, por parte de uma das primeiras Comissões de Avaliação, em classificar os cursos em A, B, C, D e E, em função da natureza dos dados disponíveis, mas também pelo clima que cercava a avaliação naquele momento", identificando esta postura como sendo um exercício de independência frente à CAPES. 
O debate sobre a construção da autonomia passa pela legitimidade da ANPEd em relação aos seus principais interlocutores e pela possibilidade de representar seus associados. As reações levaram a ANPEd a uma certa independência. Enfatizo: uma certa independência, pois ainda estamos precisando de muitos apoios do Estado. A ajuda vem do Estado, pois temos dificuldade de sermos financeiramente autônomos. Isto gera uma tensão entre os órgãos de Estado, em particular a CAPES, e os grupos da sociedade civil. $[\ldots]$

A ANPEd esteve sempre presente na tensão entre os órgãos do Estado que lidam com a educação e com a pósgraduação, especificamente, e a sociedade civil, sua organização, suas demandas e sua crítica a respeito dos problemas na educação. Ela não é uma instituição burocrática como tantas outras. Ela tem um caráter de fórum, uma prática de debates abertos. (Maria Malta)

No entanto, a relação entre a associação e os órgãos governamentais de apoio à pesquisa e à pósgraduação, ainda que conflituosa em alguns aspectos, foi de intensa interlocução. Identifica-se como preocupação comum entre ANPEd e órgãos governamentais a qualidade da produção científica na área e o necessário rigor no credenciamento de cursos, programas e instituições.

Uma análise mais detalhada das relações que a ANPEd veio estabelecendo com as agências oficiais evidencia que sua posição de interlocutora na formulação de políticas públicas para a pós-graduação no Brasil, assumida desde a sua criação, teve avanços e recuos.

Além de tensões externas, internamente a tensão sempre esteve entre os posicionamentos políticos e questões mais acadêmicas e de pesquisa. Explorando como a ANPEd se posicionou nas diversas ocasiões em que as tensões se tornaram mais explícitas, envolvendo questões de ordem política e acadêmica, Maria Malta destaca três momentos:

Inicialmente, uma postura mais combativa, que se intensificou durante a Assembléia Nacional Constituinte, no final dos anos de 1980 . Havia coesão e identidade entre os associados, em torno de propostas sobre o capítulo da educação na Constituição Federal e, posteriormente, para a Lei de Diretrizes e Bases. Já num segundo momento, nos anos de 1990, é possível identificar cisões internas à entidade, de natureza partidária. Às questões comuns emergiam respostas divergentes que expressavam preferências partidárias, e essas divergências interferiram na construção de perspectivas coletivas. E, num terceiro momento, iniciado com o primeiro Governo Lula, no qual parece ter havido recuo em posicionamentos e propostas da associação, arrefecendo tanto o debate interno, quanto o externo.

Voltando aos anos de 1980, observa Jacques Therrien:

[...] é possível verificar que as diretorias da ANPEd tiveram sua atuação, de um lado, dirigida para o desenvolvimento da pesquisa, com apoio do CNPq e da FINEP [Financiadora de Estudos e Projetos], assim como para a atuação dos grupos de trabalho; de outro, para dimensões da política educacional, por meio das Conferências Brasileiras de Educação (CBE) e do Fórum Nacional em Defesa da Escola Pública, ${ }^{8}$ por ocasião da Constituinte e da discussão da Lei de Diretrizes e Bases. A identidade da ANPEd vai-se delineando nas tensões de busca de autonomia, externamente, na primeira década, quanto a questões de política de pós-graduação com a CAPES e de política educacional com os demais responsáveis pelas $\mathrm{CBE}$ e pelo Fórum Nacional; e, internamente, na segunda década, entre o braço dos grupos de trabalho, voltados para a consolidação da pesquisa e da produção científica, e o braço Fórum de Coordenadores, com mais poder diante do crescimento dos programas e das tensões da avaliação.

${ }^{8}$ De acordo com sua Declaração de princípios e finalidades, de 21 de agosto de 2001, o Fórum Nacional em Defesa da Escola Pública constituiu-se "em uma articulação de entidades e movimentos sociais organizados da sociedade brasileira, os quais, partilhando princípios, valores, concepções e ideais semelhantes, buscam defender a educação pública, gratuita, democrática e de qualidade social para todos os brasileiros". 
A ANPEd, como fórum de debates e divulgação do que se realiza na pós-graduação, além de promover a interlocução entre pesquisadores, é reconhecida como espaço de qualificação das produções acadêmicas, por meio do Comitê Científico, dos grupos de trabalho, do Fórum de Coordenadores, das reuniões anuais, espaços estes de exposição e diálogo sobre as pesquisas e a formação realizadas em todo o Brasil.

Certamente, é preciso aprofundar a pesquisa, colher mais depoimentos para adensar essa discussão, a fim de avançar na compreensão dos fatores que permitam melhor compreender como uma instituição que, criada segundo um modelo que favorecia a tutela do Estado, conquista uma autonomia relativa, contrapondo-se ou confrontando-se até com os órgãos governamentais. Há que se reconhecer sua contribuição para os debates e proposições em momentos marcantes da história do país nesses 30 anos, além de seu protagonismo na direção da qualificação da pósgraduação e da pesquisa. Pergunta Cury:

Concomitantemente, porém, quais são os fatores que convergem para que se afirme o estigma, particularmente nas instâncias governamentais, de a ANPEd caracterizar-se por ser uma associação que apresenta muita moções, às vezes bastante radicais, constituindo-se no último reduto da vulgata marxista, e ser eminentemente protestativa? Será que isto se deve à falta de espaço para voltar a ser protagonista? à falta de compreensão dos órgãos governamentais, ou de outras áreas, da importância da educação? ou decorre de um voltar-se para questões internas da própria associação, revelando o quanto seus associados se descolaram da dinâmica social mais ampla?

\section{Pondera Maria Malta:}

[...] moções e manifestações protestativas ocorrem porque nossas assembléias são espaços abertos a debates e a manifestações dos sócios individuais, e não apenas um lugar onde representantes de programas consagram aquilo que combinaram anteriormente. Quanto à vulgata marxista, existe um pouco de razão, mas acho que a crítica vem por um outro lado, daquele pessoal que acha que chegamos ao fim da história e que as explicações totalizantes não explicam mais nada. Ainda sou antiga, acho que o marxismo, como instrumento, e não como catecismo, explica muita coisa...

\section{E conclui:}

[...] foi importante a iniciativa de aproximação com a SBPC e demais associações de área. Na gestão de Neidson Rodrigues, fui encarregada de acompanhar as reuniões internas da SBPC, para as quais eram chamados representantes de todas as áreas. Esses contatos são muito bons, pois desmistificam aqueles estereótipos que alguns possuem sobre nossa área, as pessoas confraternizam, trocam informações, a gente acaba sendo chamada para muita coisa. Por exemplo, acabei participando de reuniões da Comissão de Educação do Congresso, presididas por Florestan Fernandes, como uma das representantes da SBPC. Isso fortalecia nossas pautas da ANPEd, pois era mais uma entidade apoiando posições. Aí, quando precisamos do apoio da SBPC para nossos candidatos ao Conselho Nacional de Educação, a partir de 1996, o diálogo já existia, as pessoas já tinham um clima de confiança em relação à ANPEd, e tivemos um apoio fundamental da SBPC e da Academia Brasileira de Ciências.

\section{A ANPEd e a pós-graduação em educação: um olhar sobre alguns dados}

Com a aprovação do parecer n. 977 pelo Conselho Federal de Educação (CFE), em 1965, implantouse formalmente no Brasil a pós-graduação stricto sensu (Cury, 2005a). Em 1966 instalou-se o primeiro curso de mestrado em educação na PUC-Rio. Em 1969, pelo parecer n. 77, também do conselheiro Newton Sucupira, a exemplo do anterior, regulamentou-se a implantação da pós-graduação no Brasil, ano em que é instituído o Programa de Estudos Pós-Graduados em Psicologia Educacional da PUC-SP (Saviani, 2006). Quanto ao doutorado, os primeiros dois cursos a instalar-se segundo as novas orientações do governo federal foram, respectivamente, os da PUC-Rio e da Universidade Federal do Rio Grande do Sul (UFRGS), no ano de 1976. Desde então, os progra- 
mas de pós-graduação em educação vieram gradativamente se constituindo no espaço de realização da maior parte das pesquisas que vêm sendo produzidas em educação, sendo reiterada sua importância em estudos que focalizam a retrospectiva histórica da pesquisa educacional no Brasil. É recorrente na literatura a relação entre a implantação da pós-graduação e o aumento quantitativo da produção de pesquisa. $\mathrm{Cu}$ nha (1978), dando continuidade à consagrada periodização de Gouveia (1971), chega a afirmar que "teve início no ano de 1971 a quarta fase de desenvolvimento da pesquisa educacional no Brasil, caracterizada pelo papel preponderante desempenhado pelos programas de pós-graduação" (p. 4).

Nesses 30 anos da ANPEd e 42 anos de institucionalização da pós-graduação stricto sensu em educação, verifica-se um aumento geométrico no número de dissertações e teses concluídas, decorrentes da ampliação dos programas de pós-graduação. ${ }^{9}$ Para ilustrar esse crescimento, foram sistematizados alguns dados que possibilitam uma visão da situação atual, ao mesmo tempo em que permitem uma aproximação com a trajetória dessa expansão. ${ }^{10}$

Em maio de 2007, a área de educação contava com 83 programas recomendados pela CAPES, reconhecidos pelo CNE e homologados pelo Ministério da Educação (MEC). Desses, 36 oferecem o doutorado, além do mestrado. ${ }^{11}$ A distribuição da oferta entre

${ }^{9}$ Em relação ao volume de pesquisa educacional há também que se considerar a crescente produção dos docentes das universidades, espaço tradicional de produção de conhecimento, além de investigações que vêm sendo desenvolvidas em instituições privadas e organizações não-governamentais, que gradualmente têm ampliado sua inserção nessa área.

${ }^{10}$ Diante dos limites deste texto, serão registrados números relativos à área da educação sem a preocupação de compará-los com os da grande área de humanas e com os de outras áreas.

${ }^{11}$ Conforme o portal da CAPES, os dados apresentados foram atualizados em 4 de maio de 2007. Estão elencados os programas e cursos de pós-graduação que obtiveram nota igual ou superior a 3 na avaliação, e que, portanto, atendem ao requisito universidades públicas e privadas é apresentada na Tabela 1.

Tabela 1 - Distribuição dos cursos de mestrado e doutorado por tipo de instituição, 2007

\begin{tabular}{|l|c|c|}
\hline Instituição & Mestrado & Doutorado \\
\hline Federais & 31 & 20 \\
Estaduais & 17 & 07 \\
Privadas confessionais & 17 & 08 \\
Privadas leigas & 18 & 01 \\
\hline
\end{tabular}

Fonte: www.capes.gov.br. Acesso em: 15 maio 2007.

Evidencia-se um predomínio dos mestrados e doutorados oferecidos por instituições públicas (respectivamente $57 \%$ e $75 \%$ ), embora as instituições de ensino superior privadas sejam em maior número. Entretanto, notam-se significativas disparidades regionais na distribuição desses programas e cursos, com alta concentração na Região Sudeste, seguida pela Região Sul. Embora essas duas sejam regiões bastante populosas, observa-se que a Região Nordeste é a segunda região mais populosa do país, o que revela serem desiguais as oportunidades de formação e produção de conhecimento na área, conforme os dados constantes da Tabela 2 .

No conjunto da área, considerando o ano de 2006, quando havia 73 programas credenciados, foram titulados 2.057 mestres e 459 doutores, estando envolvidos nessa formação 1.812 docentes.

Para ter uma visão da significativa expansão do sistema de formação no âmbito da pós-graduação e, conseqüentemente, do contingente de pesquisadores

básico estabelecido pela legislação vigente para serem reconhecidos pelo MEC por meio do CNE e, em decorrência, expedirem diplomas de mestrado ou doutorado com validade nacional. Nela são incluídos os programas e cursos cujos atos de reconhecimento ou de renovação de reconhecimento já foram oficializados pelo ministro da Educação (cursos reconhecidos), como também aqueles cujas propostas foram recentemente aprovadas pela CAPES e encaminhadas ao CNE para a instrução de seus processos de reconhecimento (cursos recomendados). 
que vêm sendo formados na área, destacam-se alguns indicadores dos últimos 30 anos. Lembra-se que há 42 anos havia só um mestrado: o da PUC-Rio.

Tabela 2 - Distribuição regional dos cursos da área de educação, por níveis, 2007

\begin{tabular}{|l|r|r|r|c|}
\hline \multirow{2}{*}{ Região } & \multicolumn{2}{|c|}{ Mestrado } & \multicolumn{2}{c|}{ Doutorado } \\
\cline { 2 - 5 } & $\mathrm{n}$ & \multicolumn{1}{c|}{$\%$} & $\mathrm{n}$ & $\%$ \\
\hline Norte & 2 & 2,4 & 0 & 0 \\
Nordeste & 11 & 13,3 & 5 & 13,9 \\
Centro-Oeste & 8 & 9,6 & 4 & 11,1 \\
Sudeste & 38 & 45,7 & 18 & 50,0 \\
Sul & 24 & 29,0 & 9 & 25,0 \\
\hline
\end{tabular}

Fonte: www.capes.gov.br. Acesso em: 15 maio 2007.

Após o pioneirismo desse programa, haverá a instauração de outro mestrado em 1969, seguido de mais um em 1970, outros três em 1971 e mais sete em 1972. Chegamos, em 1984, a 27 cursos de mestrado. Os cursos de doutorado se instauram a partir de 1976. Seis anos após, em 1982, haverá sete cursos (Cury, 2005b, p. 4). ${ }^{12}$

A Tabela 3 apresenta dados mais detalhados.

Tabela 3 - Alunos titulados, matriculados no final do ano e novos, por nível, na área de educação, 1987, 1997 e 2007

\begin{tabular}{|c|c|r|r|r|r|r|r|}
\hline \multirow{2}{*}{ Ano } & Progra- & \multicolumn{4}{|c|}{ Alunos } \\
\cline { 3 - 8 } & mas & \multicolumn{2}{|c|}{ Titulados } & \multicolumn{2}{|c|}{ Matriculados } & \multicolumn{2}{|c|}{ Novos } \\
\cline { 3 - 8 } & & Mestr. & Doutor. & Mestr. & Doutor. & Mestr. & Doutor. \\
\hline 1987 & 31 & 211 & 14 & 2.123 & 169 & 567 & 32 \\
1997 & 46 & 861 & 223 & 2.892 & 1.145 & 1.025 & 479 \\
2006 & 73 & 2.057 & 459 & 5.364 & 2.491 & 2.507 & 684 \\
\hline
\end{tabular}

Fonte: www.capes.gov.br. Acesso em: 15 maio 2007.

Comparando-se o número de alunos que concluíram o curso de mestrado nos anos de 1987 e 1997, houve um aumento de mais de $300 \%$ de alunos titulados; esse percentual é de $139 \%$ quando se comparam

${ }^{12}$ A crítica mais radical a essa expansão e aos perigos de perda da qualidade ainda se encontra em Cunha (1991). os dados de 1997 e 2006. Para o doutorado, o aumento de alunos titulados entre 1987 e 1997 cresceu quase 16 vezes (1.600\%), e de 1997 para 2006 houve um aumento de $106 \%$. Os números de alunos matriculados e novos nos anos considerados reiteram a tendência de ampliação.

Com relação à pesquisa, tão importante quanto sua produção é a sua divulgação. Por diferentes meios, como livros, artigos e eventos, docentes e discentes vêm intensificando a socialização dos resultados de suas investigações, tanto no Brasil, quanto no exterior. Só para exemplificar, a Comissão de Avaliação de Periódicos da ANPEd no biênio 2006/2007 identificou, na lista gerada pelo Coletacapes com os dados de 2005, 746 periódicos nos quais se encontram publicados ensaios e pesquisas de profissionais e alunos da pós-graduação em educação. ${ }^{13}$ Desses periódicos, 190 são da área de educação e 556 são de áreas não diretamente vinculadas à educação. ${ }^{14}$

A ANPEd, expressando a ampliação da pósgraduação, contava, em junho de 2007, com a seguinte configuração: 78 associados institucionais e 1.962 associados individuais.

\section{Relação formação e pesquisa}

Apreciações sobre o movimento da pesquisa em educação e da pós-graduação, com ênfase nas articulações e posicionamentos da ANPEd, foram expressas no decorrer dos debates, cotejando elementos de

${ }^{13}$ Evidentemente, essa publicização é um feito e um mérito para a área, especialmente se levarmos em conta que há poucos anos as publicações eram escassas. No entanto, por si só, não há a garantia que quantidade represente qualidade. Há uma série de publicações questionando a "corrida pelo Lattes" (Silva, 2005); os desafios de incrementar a quantidade mantendo a qualidade (Bianchetti, 2006) e as conseqüências do publish or perish nos Estados Unidos da América (Waters, 2006), com indicações daquilo que pode vir a ocorrer aqui.

${ }^{14}$ Disponível em: <www.anped.org.br>. Acesso em: 15 maio 2007. 
retrospectiva, do cenário da educação nos tempos atuais, e apontando vicissitudes e desafios para a pesquisa em educação e a pós-graduação na área. Na origem dos programas e nas primeiras décadas de sua implantação, a preocupação central foi a de criar, consolidar e expandir os cursos de pós-graduação. Diz Bernardete Gatti:

O foco não era a pesquisa; até o final dos anos 1980, a área era pobre em pesquisa. A ênfase era colocada na formação, ia-se da formação à pesquisa, implicando amplos e consistentes currículos. Boa parte das dissertações eram densas e fundamentadas, algumas eram brilhantes, verdadeiras teses de doutorado. A pesquisa vinha como resultado de uma sólida formação.

\section{Além disso, Alceu Ferraro acrescenta:}

O tempo disponível para formação era maior do que se tem hoje. O prazo para o mestrado era de quatro anos. Havia quem fizesse em menos tempo, mas havia quatro anos para o mestrado. De fato, a pesquisa existia, mas era mais produção discente do que docente. ${ }^{15}$ Nessa época, tivemos muitos bons trabalhos de mestrandos e doutorandos, dos docentes, não. No entanto, essa produção estava concentrada em poucas instituições, a maior parte delas localizadas em São Paulo.

A ANPEd tem um papel importante no estímulo à pesquisa. A partir dos anos de 1980 a pesquisa começou a dar referência interna à ANPEd. Na $4^{\mathrm{a}} \mathrm{Reu}-$ nião Anual (Belo Horizonte, 1981) foi decidida a organização de grupos de trabalho, e os primeiros grupos foram instituídos na $5^{\mathrm{a}}$ Reunião Anual (Rio de Janeiro, 1982). No decorrer das reuniões subseqüentes, esses grupos passaram a caracterizar-se como um dos braços fortes e produtivos da ANPEd.

${ }^{15} \mathrm{Um}$ dos fatores que contribuiu para a melhoria quantitativa e qualitativa da produção docente foi a implementação das bolsas produtividade pelo CNPq, com cobranças e avaliações.
Organização de grupos de trabalho, com o objetivo de promover debates, discussões e encontros de pessoas que estejam pesquisando temas comuns ou tenham interesse nos temas do grupo. Esses Grupos de Trabalho se encontrariam por ocasião das reuniões da ANPEd e em outras oportunidades que se tornarem possíveis. Para organização dos grupos serão promovidas consultas a todos os sócios da instituição. (ANPEd, 1981, p. 3)

A inserção da pesquisa como um dos fundamentos da pós-graduação representou uma mudança profunda dentro do pouco de pesquisa que havia nas instituições. Na mesma década de 1980, intensificaram-se os debates sobre pesquisa, sentiu-se a necessidade de seu aprimoramento. Há uma consciência, mas, em contrapartida, não se sabe como fazer, não existe financiamento, não há estrutura nas universidades, não há onde publicar. É a tomada de consciência da importância da pesquisa. ${ }^{16}$

Vale registrar a iniciativa de intercâmbio entre pesquisadores, que contribuiu para a implantação e consolidação de grupos de pesquisa em educação.

O Programa de Intercâmbio entre pesquisadores da área da educação existiu entre 1981 e 1992, tendo se originado de análises da área e das agências financiadoras que apontavam a necessidade de estimular a consolidação de grupos de pesquisa no país, ajudar no aprimoramento da elaboração teórica e no tratamento metodológico das pesquisas, bem como estimular grupos emergentes. O Programa deslanchou com o estímulo e apoio da ANPEd, com financiamento do CNPq, da FINEP e da CAPES, e, em seus inícios, com a coordenação e logística a cargo da Fundação Carlos Chagas. Em seus cinco últimos anos foi gerenciado diretamente pela ANPEd, com o envolvimento dos grupos

${ }^{16}$ Todavia, uma perspectiva radical da importância da pesquisa no mestrado em educação já havia sido apresentada por Durmeval Trigueiro Mendes, quando estava sendo criado o IESAE-FGV, o mestrado em educação da Fundação Getúlio Vargas, no Rio de Janeiro (Fávero, 2005). Também foi inovadora a proposta de Joel Martins, na criação da pós-graduação na PUC-SP (Saviani, 2005). 
de trabalho. Esse programa, pelas avaliações dos participantes, foi importante para o amadurecimento de vários grupos de pesquisa, através dos encontros interinstitucionais e dos workshops, auxiliando alguns grupos de trabalho da ANPEd a tomarem corpo. Também, participantes dos estágios consolidaram-se como pesquisadores-referência em suas áreas. (Bernardete Gatti) ${ }^{17}$

A consolidação da pesquisa no âmbito da pósgraduação merece ser apreciada quanto aos seus impactos. Por um lado, há que se registrar seu aspecto positivo; por outro, a transformação da pós-graduação como o locus privilegiado da pesquisa trouxe perdas, uma vez que

\section{[...] representou a desarticulação das experiências que eram apoiadas na graduação e, até mesmo, a desarticulação entre ensino e pesquisa. Há que se reconhecer que havia bons nú- cleos de pesquisa em universidades, envolvendo os docentes da graduação. No momento em que surgiu a pós e se disse "a pesquisa mora lá", isso se desarticulou. (Alceu Ferraro)}

Constata-se, ainda, outra perda com essa priorização da pesquisa na pós-graduação, uma vez que tornou secundária a formação para a docência. Hoje se está questionando o que o mestrado e o doutorado têm contribuído para a docência. Certas habilidades para docentes não estão contempladas na formação do pesquisador. ${ }^{18}$ Do ponto de vista acadêmico, particularmente das relações entre pós-graduação e pes-

\footnotetext{
${ }^{17}$ Sobre a formação de grupos e redes, ver Gatti (2005).

18 Ver a tese de Bazzo, Constituição da profissionalidade docente na educação superior: desafios e possibilidades (2007). Entre outros temas, sua pesquisa evidenciou senão a ausência de formação para a docência nos cursos de pós-graduação, pelo menos sua secundarização em relação à formação para a pesquisa. Essa perspectiva, diz a autora, produz desdobramentos importantes para a temática da profissionalidade, pois determina o que os professores priorizarão em seu cotidiano. A maioria dos entrevistados concluiu que usava muito mais suas horas de trabalho em investigações: no laboratório, no campo, nos congressos e encon-
}

quisa, levantou-se a hipótese de ter-se constituído uma anomalia congênita, uma vez que se apresentou como fragmentado aquilo que deveria ser concebido como indissociável. E isso pode ficar mais evidente se tivermos presente o predomínio do paradigma da "formação de professores" até meados da década de 1990, para, em seguida, induzir-se a supremacia do paradigma da "formação de pesquisadores" (Kuenzer \& Moraes, 2005).

\begin{abstract}
[...] é problemática a associação estreita entre pós-graduação e pesquisa. Nos anos de 1970 estava claro que pósgraduação era curso. Houve uma inversão: hoje se faz pós para fazer pesquisa, mas não há aprofundamento. A avaliação, da maneira como está constituída pela CAPES, avaliando docentes como pesquisadores, não contribui para o aprimoramento da pós enquanto curso; é valorizado o pesquisador, não o docente. (Bernardete Gatti) ${ }^{19}$
\end{abstract}

Contribui para que predomine essa perspectiva a supervalorização da produtividade, medida pelo número de publicações, gerando uma verdadeira "corrida pelo Lattes" (Silva, 2005). Em conseqüência, há uma visão de que o curso é bom se os professores estão produzindo, publicando.

No debate, além de serem levantados questionamentos a respeito do descuido com a docência ao se privilegiar a pesquisa, houve muitas manifestações a respeito do quanto vieram sendo modificadas as condições de trabalho daqueles que se dedicam à pósgraduação - e à vida universitária em geral -, com evidentes prejuízos para a qualidade do trabalho, bem como para a vida pessoal, uma vez que todos estão

tros da área, escrevendo relatórios e artigos etc. Nesse aspecto, fazia-se uma espécie de mea culpa coletiva pela constatação de que ao ensino restavam as horas obrigatórias das aulas na grade curricular.

${ }^{19}$ Em 1986, no seminário de comemoração dos 20 anos de criação do mestrado da PUC-Rio, Bernardete Gatti já discutiu a dificuldade de formar professores ou pesquisadores no mestrado em educação (ver Gatti, 1987a). 
sendo submetidos a um processo de extensão e intensificação da jornada de trabalho. No que diz respeito especificamente ao ensino e à investigação, Alceu Ferraro afirma:

Há que se avaliar as condições de trabalho. Está difícil hoje se dedicar à docência e à pesquisa. Dos anos de 1990 para cá houve uma brutal intensificação do trabalho, questão essa que merece ser estudada. É preciso analisar o que está acontecendo e as suas conseqüências para o ensino e a pesquisa. Produzir algo novo está difícil, não há mais tempo para pensar, para refletir. O que vale é a quantidade.

Esse processo está exigindo que, mesmo em relação à pesquisa que vem sendo produzida no âmbito dos programas, sejam analisados seus resultados, do ponto de vista da qualidade. Enfatiza Bernardete Gatti:

Não considero o mestrado como produção de pesquisa; é uma iniciação. Até o final dos anos de 1980 os cursos eram mais densos. À medida que foi diminuindo o tempo para sua realização e o doutorado passou a ser o foco, o mestrado assumiu o caráter de iniciação. Raramente se encontra uma análise de fôlego em uma dissertação. Aliás, nem no doutorado. As dissertações são verdadeiros estudos exploratórios... Preparação para alguma coisa.

\section{E complementa:}

Muitos colegas estão achando que realmente o mestrado está levando à produção de um trabalho extremamente ligeiro. É claro que a comparação é com o que a gente conheceu. Essa produção está se tornando problemática. Nossa área é reflexiva, diferente de áreas mais duras, em que é possível fazer um pequeno experimento, e isso já ser considerado um mestrado. Em nossa área, para muitos alunos, o mestrado é o final, a maioria não dá continuidade no doutorado. Portanto, indaga-se: com que idéia de pesquisa sai esse mestrando? É pouco tempo para amadurecer algumas idéias.

Deve-se ressaltar que essas idéias retomam e reforçam questões que de longa data são apontadas.
Desde o início da década de 1970, uma série de autores (Gouveia, 1971; Gatti, 1987b; Grzybowski, 1987; Paoli, 1985) vem apontando para o problema da pesquisa educacional no Brasil e a preparação de pesquisadores, via pós-graduação, na interface ensino e pesquisa. A tônica dessas discussões foi assim sintetizada por Sousa (1994, p. 28):

[...] a apreciação da qualidade do que é produzido deve ter em conta os contornos dos programas de pós-graduação que, sem dúvida, refletem-se nas pesquisas que vêm sendo geradas. O modo como usualmente tem se estruturado tais programas não favorece que a criação do conhecimento se constitua no eixo organizador dos cursos de pós-graduação, em torno do qual se articularia a atividade de ensino. O que se observa é que o ensino e a pesquisa não são conduzidos numa perspectiva integrada, sendo vivenciados como momentos estanques.

Particularmente a partir dos anos de 1990, a ANPEd tem procurado induzir a melhoria da qualidade da pesquisa por meio de iniciativas que possibilitem a disseminação de critérios de qualidade. Os participantes do debate destacaram frentes protagonizadas pela associação que vêm contribuindo para a qualificação da área:

a) criação do Comitê Científico, decidida no Encontro de Avaliação e Planejamento realizado na PUC-SP, em novembro de 1989, passando a funcionar na preparação das reuniões anuais a partir da $13^{\mathrm{a}}$ Reunião Anual (São Paulo, 1990). Embora a sua criação tenha sofrido resistências, foi um marco passar a ter os trabalhos selecionados por uma comissão científica, valorizando a pesquisa e exigindo melhor sistematização e qualificação das comunicações a serem apresentadas nos grupos de trabalho. Como afirma Jacques Therrien, "a existência de comitês científicos para outros eventos, entre eles os seminários regionais de pesquisa, criou uma nova cultura na área"; 
b) promoção de sessões especiais e mesas-redondas, com a integração de vários grupos de trabalho, assim como a realização de minicursos nas reuniões anuais, ampliou a ação da ANPEd, que passou a assumir também uma postura formativa, e não apenas seletiva;

c) assunção e promoção de concursos de pesquisa sobre determinadas questões constituise em um desafio, possibilitando à ANPEd ganhar experiência na explicitação de referências para julgamento de projetos de pesquisa e funcionar como agência de apoio para sua realização;

d) estímulo à realização dos seminários de pesquisa regionais (as "anpedinhas") causou impacto positivo, criando outros espaços de formação, possibilitando que alunos de pósgraduação se pudessem deslocar mais proximamente e propiciando que sejam atendidas e respeitadas especificidades regionais. Nesse sentido, afirmou Jacques Therrien, "no Nordeste, procura-se também estimular a participação de alunos da graduação, especialmente os bolsistas PIBIC [Programa Institucional de Bolsas de Iniciação Científica]". Observou-se, no entanto, ser importante que as reuniões regionais atendam às especificidades locais;

e) publicação da Revista Brasileira de Educação, que, apontando para um padrão de qualidade internacional, tornou-se uma referência em todos os programas.

Além dessas ações, merece destaque a atuação da ANPEd na interlocução com a CAPES e com o CNPq. Especificamente em relação à CAPES, instância do governo federal responsável, desde 1976, pela avaliação dos programas, têm sido reiterados os questionamentos dos critérios adotados, bem como o encaminhamento de propostas, iniciativas essas que expressam uma dada noção de qualidade da pesquisa e pós-graduação, construída no interior da associação. Ressalta-se que os questionamentos se direcio- nam à forma como é feita a avaliação, aos critérios homogêneos para áreas tão diversas etc., e não à avaliação em si. Considera-se que esta é necessária e importante; o que se reivindica não é sua dissolução, mas sim sua qualificação.

Por oportuno, Bernardete Gatti lembra que, em sua origem:

[...] não havia uma preocupação explícita da CAPES de avaliar a pesquisa, o foco era a formação, a implantação dos cursos de mestrado e dos cursos de doutorado. Seu papel era desenvolver formação. O CNPq é que teve a iniciativa de investigar, a partir da pós-graduação, o que estava sendo produzido de pesquisa. O primeiro trabalho nessa direção foi o de Aparecida Joly Gouveia, em 1978, e o meu, em 1982; depois houve o extenso trabalho coordenado pelo Cury, em 1992. ${ }^{20}$ A preocupação com a questão da pesquisa veio pelo $\mathrm{CNPq}$, que queria ver o impacto da pós-graduação na pesquisa. Isso deu condições para que a CAPES se apropriasse de um tipo de avaliação um pouco estranha à formação, porque ela se apropriou dos esquemas de CNPq e da FAPESP [Fundação de Amparo à Pesquisa do Estado de São Paulo] para avaliar cursos. A preocupação do CNPq era legítima, sem dúvida, porque concedia auxílios, bolsas, quer dizer, entrava no nicho que lhe era próprio.

\section{Articulação da ANPEd com órgãos de fomento e avaliação}

Os debates focalizaram principalmente a CAPES e o CNPq. A articulação da ANPEd com a CAPES foi caracterizada em dois momentos. Inicialmente havia uma relação de cooperação; os representantes de área (chamados de "presidentes") eram ouvidos em relação aos procedimentos e critérios de avaliação. ${ }^{21}$ Nessa

${ }^{20}$ Avaliação \& perspectivas na área de educação 1982-1991. Porto Alegre: ANPEd, 1993. Disponível em: <www.anped.org.br/ documentos $>$.

${ }^{21}$ Por causa do crescimento da pós-graduação como um todo, atualmente o CTC é formado por representantes das grandes áreas, 
época, todos os representantes de área integravam o Comitê Técnico-Científico (CTC) da CAPES e participavam das reuniões para efeito de elaboração de diretrizes, fixação de critérios de expansão, alocação de bolsas e outros assuntos, como visitas aos programas. Os presidentes das comissões da área de educação discutiam esses aspectos com a ANPEd, e as indicações resultantes dessas discussões tinham impacto nos encaminhamentos adotados pelo órgão para a avaliação e o fomento. Posteriormente, a CAPES passou a assumir uma postura mais diretiva, avocando a si, de modo isolado em relação às entidades e associações, o delineamento dos processos e padrões de avaliação e financiamento. A partir dessa postura vai tornando-se evidente que a idéia de representação está esvaziada. De um lado, a CAPES pouco ou nada ouve o representante e, de outro, pergunta Bernardete, "qual o sentido de existir um representante de área se este não se reporta aos seus pares para encaminhar as decisões? A burocracia vigente está beirando o autoritarismo?".

Há o reconhecimento, no entanto, de que, apesar do predomínio de uma postura hierárquica, verticalizada, no processo de avaliação da CAPES, bem como dos desdobramentos sobre o financiamento, continua existindo uma flexibilidade que não está sendo aproveitada pelos representantes da nossa área. Isso pode ser inferido quando se observam os critérios adotados em outras áreas nas quais há maior flexibilidade e outro nível de exigência em alguns quesitos.

A sistemática vigente até meados dos anos de 1990 induzia a uma maior solidariedade entre os programas; atualmente sobressai uma maldisfarçada e talvez induzida competição. Inclusive, havia um diferencial na década de 1980 até meados da década de

indicados pelas representações das subáreas e nomeados pelo presidente da CAPES. Juntamente com a direção da CAPES, o CTC compõe uma poderosa instância burocrática, que toma decisões que muitas vezes vão de encontro às propostas das comissões de avaliação das áreas (ver Horta \& Moraes, 2005).
1990: as visitas de acompanhamento, cujos relatórios eram acoplados à avaliação. Havia visitas interprogramas, financiadas pela CAPES, justamente para complementar a avaliação; não se fazia a avaliação com base apenas nos relatórios dos programas. Às vezes havia programas que recebiam três visitas, por várias razões, inclusive pelo apontamento de dificuldades. Tinha-se a oportunidade de observar a dinâmica do programa - se havia um clima cooperativo, se havia muito individualismo, se havia a nucleação da produção, a presença dos alunos, o impacto regional do programa, entre outros aspectos. Esse elemento era fundamental. Agora, aprende-se a fazer relatório e preencher a ficha, e com isso os programas estão ficando espantosamente semelhantes.

Observou-se que há uma expectativa da CAPES de que a avaliação resulte em uma discriminação dos programas em função de sua qualidade:

Existe uma forma que é burocrática, que está beirando o autoritarismo e que não estamos percebendo, ou estamos percebendo sublinearmente. A direção da CAPES quer que haja uma curva normal, tantos por cento com 5 e tantos por cento com 4. Então, são introduzidos elementos distintivos, que possibilitem discriminar os programas. Em termos de educação, impor a curva normal é um absurdo. A avaliação deveria ser um elemento de estímulo, e não de punição. (Jacques Therrien) ${ }^{22}$

Além disso, o poder indutor da avaliação no sentido de promover a melhoria da pós-graduação precisa ser problematizado. Talvez o que esteja ocorrendo seja um aprimoramento na elaboração de relatórios: o relatório é que é bom, não necessariamente o programa. Também se problematiza o deli-

${ }^{22}$ A respeito da função punitiva da avaliação da CAPES, ver Sguissardi (2006). Por sua vez, Ramalho e Madeira (2005) analisam a reestruturação dos programas de pós-graduação em educação do Norte e do Nordeste como reação positiva da área diante dos resultados da avaliação realizada em 1998. 
neamento que vem sendo adotado para avaliar os programas, pois este está mais voltado para indivíduos do que para cursos. A questão que se coloca é: será que um curso é resultado da somatória da produção individual?

É perceptível o pequeno impacto da avaliação no processo formativo no âmbito dos cursos de mestrado e de doutorado, na qualidade do que vem sendo produzido:

Ninguém mais tem tempo para parar e pensar, escrever um artigo tranqüilamente, produzir alguma coisa nova. Tudo é feito em cima do joelho, correndo, porque tem mais três coisas na filla para fazer. Não há mais tempo para escrever com calma, para pensar, para refletir. A avaliação não incide sobre a qualidade, a quantidade tem um peso muito grande $[. .$.$] a avaliação tende a se transformar num elemen-$ to traumatizador, num elemento inibidor, num elemento de mero controle. No entanto, ela deveria ser um elemento estimulador, provocador, representando mais um desafio do que propriamente punição. (Alceu Ferraro)

Vale lembrar que até meados da década de 1990 os programas em consolidação não recebiam nota ou letra na avaliação. Eram denominados "programa em desenvolvimento". E mais: recebiam verbas, recebiam bolsas, recebiam um consultor que ia atuar junto a eles para melhorar seu desempenho. Entramos numa outra filosofia de competitividade agressiva, nada pedagógica. Sem dúvida, uma das conseqüências desse processo foi a vinculação da avaliação ao financiamento; a partir do momento em que começou a expansão do número de cursos sem que se fizesse acompanhar de uma ampliação no orçamento das agências.

Por sua vez, a relação entre ANPEd e CNPq teve um bom começo. Bernardete Gatti ressaltou:

Se, por um lado, a ANPEd já criara, desde o início, rupturas, buscando espaços mais democráticos, por outro lado assumiu a Superintendência de Desenvolvimento Social do $\mathrm{CNPq}$ uma equipe liderada por profissionais com participação política ativa, comprometida com a educação.
Nesse momento, foi formada uma comissão consultiva da área da educação no CNPq. Essa comissão produziu um documento do qual constavam algumas indicações de ações para o CNPq, na área da educação. Dentre elas, destaca-se a valorização do intercâmbio entre pesquisadores, que só poderia ocorrer com o apoio dessa agência. Essa idéia veio de discussões com membros da diretoria da ANPEd. Essa comissão também sugeriu a criação de um comitê científico específico para a área de educação, ecoando demandas da diretoria da ANPEd e de muitos pares. Outra vitória da ANPEd, conquistada com a atuação dos membros internos ao $\mathrm{CNPq}$ e do pessoal das universidades, foi a indicação dos membros dos comitês feita pela área, via ANPEdEssa indicação se fazia após consulta a todos os programas. Foi um período de muita luta, e reconhece-se que o comitê de educação só sobreviveu devido ao apoio que a ANPEd sempre lhe deu.

Foi, por fim, mencionada a importância da relação da ANPEd com outras associações, como a SBPC, o Centro de Estudos Educação e Sociedade (CEDES), da Universidade Estadual de Campinas (UNICAMP), a Associação Nacional de Educação (ANDE) e a Associação Nacional pela Formação de Profissionais da Educação (ANFOPE), conforme afirma Maria Malta:

A atuação da ANPEd ganhou uma papel diferente conforme o espaço que ocupou, e isso ocorreu propositalmente, intencionalmente. Nas reuniões da CBE, nas quais a ANPEd manteve parceria intensa com o CEDES e a ANDE, o papel de interlocução da ANPEd foi de mobilização e divulgação das pesquisas para um público mais amplo, formado por professores e estudantes; com a SBPC, ao lado da divulgação das pesquisas e do debate acadêmico, realizou-se uma parceria de militância, de luta pela democratização da escola e do ensino.

\section{Perspectivas da ANPEd em relação à pesquisa e à pós-graduação}

O debate acerca de possibilidades de consolidação ou ampliação de iniciativas da ANPEd no senti- 
do de fortalecer sua atuação como indutora da melhoria da qualidade da pesquisa e da formação em pós-graduação, e como interlocutora na formulação e implementação de políticas públicas de educação, contemplou aspectos diversos. Eles são a seguir registrados.

Apoio aos programas de pós-graduação

Foram feitas sugestões concretas de como a ANPEd pode assumir o protagonismo em alguns pontos. Em primeiro lugar, o apoio aos programas de pós-graduação é entendido como fundamental, com vista a criar uma rede de cooperação entre os programas, docentes e alunos. "Eu vejo com otimismo a relação da associação com os programas, com os sócios institucionais, entendo que é onde a ANPEd tem espaço para avançar”. Enquanto a CAPES tem promovido a competição entre os programas, "a ANPEd viria no contraponto, organizando o trabalho com base na cooperação". Verifica-se atualmente que, "em algumas áreas, pesquisadores escondem dados e análises de seus colegas até que sejam publicados. Essa lógica está chegando para nós da educação, e é complicado. É preciso entrar na contramão. Produzir conjuntamente artigos, softwares, intercâmbio de professores seniores etc. É o momento para fazer isso" (Cury).

A concretização desses apoios - embora possa ser também financeira, complementar ao que os programas já fazem ou pretendem fazer - deveria ser traduzida na mediação com instituições congêneres de outros países, visando garantir a ida de brasileiros ao exterior e a vinda de convidados estrangeiros aos programas. Poder-se-ia partir das experiências já acumuladas. Por exemplo, a vinda de alguns pesquisadores estrangeiros para participar das reuniões anuais é muitas vezes aproveitada para circular por diversas instituições. Sugere-se seja dado um caráter mais sistemático e direcionado a essas iniciativas, pois o que tem predominado são desdobramentos em função de interesses e disponibilidades.

Considerando que os coordenadores de progra- mas têm hoje pouco tempo de permanência na função, principalmente nas universidades públicas, mas desempenham papel de grande importância, seria fundamental sistematizar a formação desses coordenadores e apoiar a disseminação de informações de que precisam. ${ }^{23}$ Esse é um desafio a ser enfrentado pela ANPEd, pois os coordenadores estabelecem relações entre os diversos programas e as pró-reitorias das universidades a que pertencem, com as agências de fomento à pesquisa e coordenação da pós-graduação, e são membros do Fórum de Coordenadores, cujo papel é debater e propor perspectivas de fortalecimento dos programas de todo o país, e não apenas discutir a avaliação.

O apoio a cursos de formação também pode contribuir para estreitar a necessária ligação entre pesquisa e formação. Isso dependeria da identificação de áreas que apresentam fragilidades. A ANPEd deve identificar e mapear as fragilidades dos programas e organizar intervenções positivas e de apoio à solução de problemas que, supostamente, não dizem respeito a apenas um programa. Seria importante contribuição para redirecionar as finalidades a que vêm servindo as avaliações, com impactos na melhoria da qualidade dos cursos.

Além do apoio aos programas existentes e aos seus coordenadores, outro ponto que está a merecer atenção especial é a criação de novos cursos, especialmente nas regiões que apresentam desequilíbrios, como a Amazônia e o Centro-Oeste.

${ }^{23}$ Iniciativa nessa direção foi tomada pelo Fórum de Coordenadores, convidando Lucídio Bianchetti para, durante reunião realizada na Universidade de Brasília (UnB), em março de 2006, fazer a comunicação "Coordenador de programa de pós-graduação: um burocrata? Um gerente? Um pesquisador? Os dilemas da administração acadêmico-pedagógico-burocrática dos programas de pós-graduação em educação em período de mudança". O texto que embasou a comunicação deverá ser publicado em futuro próximo. 
Atuação da ANPEd na divulgação de pesquisas e em abordagens formativas na pós-graduação

A manutenção ou a ampliação dos meios de divulgação de pesquisas e informações entre os programas, docentes e alunos da pós-graduação foi tema que ocupou o grupo debatedor. "Temas não necessariamente ligados à pós-graduação, mas que exigem posicionamento da associação, devem ser discutidos pela ANPEd. É necessário criar canais de debates e sistematizar as discussões que gerem propostas mais institucionais, por meio de uma linha de publicações sobre temas candentes" (Jacques Therrien).

Cury e Bernardete Gatti insistiram na retomada sistemática dos intercâmbios avançados: eventos em que pesquisadores experientes em temáticas específicas se encontrariam para trocar informações e aprofundar reflexões teóricas e metodológicas. Encontros como esses também precisam ser apoiados entre grupos de pesquisa de diferentes regiões e universidades para debater e checar metodologias e achados.

Ressaltou-se ainda que a organização de seminários temáticos, reunindo pequenos grupos, pode ser uma estratégia eficiente para a produção de documentos e publicações sobre temas relevantes. O produto desses seminários poderia motivar a retomada da série Documentos da ANPEd, como importante apoio aos programas. A divulgação desses textos poderia dar-se em versão eletrônica, por meio do portal da ANPEd, e também em versão impressa, enviada a cada um dos programas.

Outra iniciativa que poderia ser retomada seria relacionada às oficinas desenvolvidas para a formação de editores de revistas científicas, que foram coordenadas pela ANPEd e realizadas com apoio de universidades e do Instituto Nacional de Estudos e Pesquisas Educacionais Anísio Teixeira (INEP). Também deveria ser refeito o levantamento dos periódicos existentes na área e aprofundada suas avaliações, não apenas para subsidiar a elaboração da
Qualis da CAPES, mas para encaminhar uma avaliação da qualidade dos artigos publicados. ${ }^{24}$

Cury sugere ainda que a ANPEd disponibilize no portal todo o acervo de resumos de teses e dissertações do período 1973-1997, com um sistema de busca ágil e eficiente, e que estabeleça link com o portal da CAPES, no qual estão sendo divulgados resumos a partir de 1998. Os "estados do conhecimento" produzidos pelos grupos de trabalho, com apoio financeiro do INEP e divulgados por essa mesma agência, têm sido extremamente úteis e deveria ser planejada a cobertura de outras temáticas.

\section{Organização interna da ANPEd}

Considerados marcos em relação aos avanços da história da ANPEd, os grupos de trabalho multiplicaram-se, chegando atualmente a 23 , havendo sobreposições, uma vez que se organizam em disciplinas, temas e por níveis de ensino. Segundo Bernardete Gatti:

É necessário rediscutir o significado dos grupos de trabalho. O que vejo hoje é que temos grupos de diferentes naturezas epistêmicas, de recortes diferentes. Temos os grupos disciplinares: filosofia, psicologia, sociologia; temos os grupos de ensino e temos grupos temáticos. Acho que chegou a hora de fazermos uma discussão sobre o significado dos grupos de trabalho no momento contemporâneo da pesquisa educacional, os dilemas e problemas que vêm sendo colocados e os modos como estes dilemas e problemas vêm sendo tratados. Há alguns avanços muito importantes na pesquisa educacional. Estamos criando um novo modo de pesquisar, superando alguns modelos in-

${ }^{24}$ Foram realizadas duas oficinas para editores, a primeira em Campo Grande, em 2003, e a segunda em Natal, em 2005. Também foram feitos dois levantamentos dos periódicos da área, o primeiro no bojo da Avaliação \& perspectivas na área de educação 1983-1991, o segundo, mais completo, em 1998, cujos resultados foram publicados na Revista Brasileira de Estudos Pedagógicos (Ortega, Fávero \& Garcia, 1998). 
vestigativos e criando outras instâncias de investigação a partir de temas provocativos. Então, não está mais interessando se determinado tema é da órbita do ensino fundamental ou do ensino médio; está interessando a relação pedagógica e as pessoas nela envolvidas, seja com crianças e adolescentes ou jovens e adultos. As pesquisas de maior densidade estão caminhando numa direção que chamo de temática, e, por isso, fazendo interfaces de vários segmentos envolvidos, nos quais a questão está presente. Exemplos disso são os trabalhos sobre gênero e corpo, que não têm sido segmentados. Essa é uma tendência internacional que tem a ver também com a questão da interdisciplinaridade; não está no discurso, mas nas formas de investigar. Isto poderia acarretar uma revisão da composição dos grupos de trabalho. Provocar essa discussão é um desafio para a ANPEd: delinear um cenário, um horizonte de discussão, para onde caminhar na composição dos grupos de trabalhos num futuro próximo, superando divisões que estão criando guetos. Temos de reconhecer que há guetos e que esses guetos poderiam ser superados se trabalhássemos, por exemplo, com temáticas que são relevantes hoje e que, entendo, manterão essa relevância por alguns anos. Combinar permanência e flexibilidade. Permanência porque há temáticas que vão perpassar a questão da pesquisa e da política educacional na construção do conhecimento; e flexibilidade porque há temáticas que vão ser superadas, aparecendo outras. Parece-me mais simples encerrar o trabalho dos grupos cujas temáticas já foram superadas por uma série de condições, e assumir outras temáticas que estão emergindo como relevantes. Criar-seia uma flexibilidade, sem a necessidade de multiplicar grupos. O que está acontecendo é que aparecem novas temáticas e, ao invés de vermos onde elas se encaixam, abrimos novos grupos de trabalho.

\section{Relações da ANPEd com instituições, docentes e pesquisadores internacionais}

O estabelecimento de relações simétricas e recíprocas entre instituições, docentes e pesquisadores brasileiros e internacionais pode ser favorecido pela atuação da ANPEd. Entendendo que o simples convite individual a docentes e pesquisadores não é suficiente para o estreitamento de laços, propõe-se a identificação de associações semelhantes à ANPEd em outros países e o estabelecimento de relações institucionais a partir dessa identificação. Realizar ações de aprofundamento de relações entre instituições latino-americanas é um desafio que deve estar em horizonte próximo, para a ANPEd. Isso demandaria o estabelecimento de termos de cooperação e de planejamento para os próximos anos, e essa iniciativa de cooperação regional poderá trazer grandes avanços para as pesquisas.

A consolidação de um patamar de relações internacionais mais sólidas exigiria a abertura de espaços para professores estrangeiros no Brasil e de professores brasileiros no exterior, e teria ainda como contrapartida a abertura de espaços institucionais para a ANPEd.

Como estratégias desencadeadoras da intensificação dessas relações foram mencionadas a elaboração de projetos de intercâmbio e a ampliação da presença institucional de pesquisadores estrangeiros nas reuniões anuais.

\section{Relações da ANPEd}

com outras associações de pesquisa

A legitimidade institucional e política da ANPEd concretiza-se também em sua relação com as demais instituições de pesquisa. Intensificar essas relações parece ser um dos desafios para os próximos tempos. Em relação à área das ciências humanas, a ANPEd poderia convidar os presidentes das associações dessa área, congregando-a em um simpósio, como sugere Cury. A cooperação ou articulação entre ANPEd e SBPC foi mencionada como ação necessária para o fortalecimento político da associação, sobretudo ante os órgãos governamentais. Ainda segundo Cury, "associações que fazem interface com a área da educação são também espaços de articulação e troca entre pesquisadores e docentes da pósgraduação". 


\section{Interlocução da ANPEd}

com as políticas públicas

Algumas das medidas adotadas em termos de políticas públicas, sobre as quais não há consenso, precisam ser incorporadas à pauta de debates da ANPEd. Dentre elas, foram destacadas a pós-graduação a distância, a condição de estudos para o aluno-trabalhador e a avaliação.

A educação a distância já é uma realidade e, na opinião de Cury, "é um campo sobre o qual é preciso começar a pensar com muita seriedade, sem nenhum tipo de lero-lero, mas com muito realismo. É um assunto que não pode ser tratado por moções aprovadas na assembléia geral, colocando-se a área sistematicamente contra". Mas Bernardete Gatti pondera: "Do jeito que está a educação a distância, eu sou contra. Não contra a educação a distância, mas contra o jeito como as universidades estão se apropriando desse espaço. Eu acho que essas coisas não são refletidas. Enfim, é algo que a ANPEd precisa pautar para discussão".

Foi destacado que, na área de educação, está cada vez maior o número de pós-graduandos trabalhadores, o que não ocorre em todas as áreas, sendo urgente analisarem-se as condições desses alunostrabalhadores em relação às exigências da pós-graduação.

Essa realidade em nossa área é diferencial. Nas áreas de lógica e de exatas há poucos alunos-trabalhadores; de maneira geral o aluno vai numa seqüência de graduação, mestrado e doutorado, com bolsa. A maioria dos alunos tem dedicação exclusiva. Não é o que ocorre na área de educação e também nas de serviço social, administração, letras. A discussão do aluno-trabalhador nos cursos de pós-graduação precisa ser feita com urgência. Que condições são dadas para esse aluno-trabalhador poder fazer e concluir o seu mestrado ou seu doutorado? Decorre daí o alto número de desistências nos últimos anos. O aluno não agüenta trabalhar, dar aula e dividir o tempo com o mestrado ou o doutorado. Não tem tempo para leitura, por causa do cansaço excessivo. Essa condi- ção do aluno- trabalhador precisa ser discutida, contemplando, por exemplo, os prazos, a dinâmica vigente nos cursos. (Bernardete Gatti)

Concordando, Cury acrescenta que essa questão dos prazos tem que ser debatida também com a CAPES. Mas insiste sobre a necessidade de estudos e investigações, com vista a embasar a interlocução: "Para debater com a CAPES é preciso apresentar dados e, para isso, é preciso produzir estudos".

Para dar encaminhamento a essa questão, foi sugerido que a ANPEd coordene uma pesquisa junto aos programas, objetivando a coleta de dados acerca de evasão, situação do aluno-trabalhador etc., que permitisse subsidiar uma proposta de revisão de critérios hoje vigentes quanto à concessão de bolsas e prazos para conclusão dos cursos.

Foi destacada a centralidade da avaliação na conformação das políticas de pós-graduação e pesquisa, caracterizando-se como um desafio a ser enfrentado no debate com os órgãos governamentais, particularmente com a CAPES. Em momentos anteriores, a ANPEd foi parceira da CAPES na definição de critérios, posição que precisa ser retomada.

Houve um afastamento das discussões da comissão de avaliação da CAPES em relação à ANPEd. E a ANPEd perdeu muito espaço nessa questão. A grande autonomia que a comissão tem hoje, pois é ela que determina os detalhes da avaliação, deve ser debatida, porque a comissão é formada por nossos pares. (Bernardete Gatti)

A avaliação apresenta-se como tema recorrente em razão dos impactos e desdobramentos que suscita, além de que pouco se tem conseguido alterar na lógica que vem orientando a sistemática em curso há vários anos, apesar de terem sido colocados, pela própria ANPEd, modelos alternativos. A associação é, por sua natureza, interlocutora legítima e qualificada para debater e propor encaminhamentos em relação a esses e aos demais temas que dizem respeito à pesquisa e à pós-graduação no Brasil. Nessa perspectiva, Bernardete Gatti afirma: 
"Concebo a ANPEd como um fórum de pensadores, um fórum de pensadores críticos, um fórum de pensadores críticos sensíveis".

\section{Finalizando e provocando a continuação do debate}

A partir das contribuições dos presentes neste encontro, acreditamos que estão postas oportunas e instigantes questões que se espera estimulem e ampliem o diálogo acerca dos rumos da pós-graduação e da pesquisa em educação no Brasil, no âmbito da área da educação, em um clima pluralista, envolvendo interlocutores de outras áreas, associações e instituições.

Não se teve a pretensão de esgotar nem as questões elencadas para o debate, nem sua abordagem. Essa é uma leitura, dentre outras possíveis, sobre a pós-graduação e a pesquisa em educação no Brasil, e o protagonismo da ANPEd. Daí se configurar como um início de conversa que possibilitou trazer novos olhares sobre a história da associação, bem como suscitar controvérsias, perspectivas e desafios futuros.

\section{Referências bibliográficas}

ANPEd - Associação Nacional de Pós-Graduação e Pesquisa. Boletim ANPEd, Rio de Janeiro: ANPEd, v. 9, n. 1, p. 3, out. 1981.

BAZZO, Vera Lúcia. Constituição da profissionalidade docente na educação superior: desafios e possibilidades. 2007. Tese (Doutorado em Educação) - Faculdade de Educação, Universidade Federal do Rio Grande do Sul, Porto Alegre, 2007.

BIANCHETTI, Lucídio. Juracy C. Marques: primórdios e expansão da pós-graduação stricto sensu em educação na Região Sul. Revista Brasileira de Educação, Rio de Janeiro: ANPEd, n. 30, p. 151-161, set./dez. 2005 (Entrevista publicada no número especial sobre os 40 anos da pós-graduação em educação no Brasil).

. Os desafios de escrever dissertações/teses: como incrementar a quantidade e manter a qualidade com menos tem- po e menos recursos. In: BIANCHETTI, Lucídio; MACHADO, Ana Maria Netto (Orgs.). A bússola do escrever: desafios e estratégias na orientação e escrita de teses e dissertações. 2. ed. São Paulo: Cortez; Florianópolis: Editora da UFSC, 2006. p. $165-185$.

BIANCHETTI, L.; FÁVERO, Osmar. Maria Julieta Costa Calazans: o papel do IESAE e da ANPEd na pós-graduação em educação. Revista Brasileira de Educação, Rio de Janeiro: ANPEd, n. 30, p. 139-150, set./dez. 2005 (Entrevista publicada no número especial sobre os 40 anos da pós-graduação em educação no Brasil).

CALAZANS, Maria Julieta Costa. O papel do IESAE e da ANPEd na pós-graduação em educação. Entrevista a Lucídio Bianchetti e Osmar Fávero. Revista Brasileira de Educação, Rio de Janeiro: ANPEd, n. 30, p. 139-150, set./dez. 2005 (Número especial sobre os 40 anos da pós-graduação em educação no Brasil).

CAMBI, Franco. História da pedagogia. São Paulo: Editora da UNESP, 1999.

CARVALHO, José Carmelo Braz de. Origens da ANPEd: de instituída a instituinte. Revista Brasileira de Educação, Rio de Janeiro: ANPEd, n. 17, p. 134-139, maio/ago. 2001.

CUNHA, Luiz Antônio. Os (des)caminhos da pesquisa na pósgraduação em educação. In: SEMINÁRIO SOBRE A PRODUÇÃO CIENTÍFICA NOS PROGRAMAS DE PÓS-GRADUAÇÃO EM EDUCAÇÃO. Brasília: MEC/CAPES, 1978. p. 315.

Pós-graduação em educação: no ponto de inflexão? Cadernos ANPEd, nova fase, n. 3, p. 39-48, 1991.

CURY, Carlos Roberto Jamil. Quadragésimo ano do Parecer CFE n. 977/65. Revista Brasileira de Educação, Rio de Janeiro: ANPEd, n. 30, p. 7-20, set./dez. 2005a (Número especial sobre os 40 anos da pós-graduação em educação no Brasil).

40 anos de pós-graduação em educação no Brasil: situação e desafios. S.1.: s. ed., 2005b (mimeo.) (Conferência proferida na PUC-Rio em 31 de outubro).

FÁVERO, Maria de Lourdes de Albuquerque. Durmeval Trigueiro Mendes e sua contribuição à pós-graduação em educação. Revista Brasileira de Educação, Rio de Janeiro: ANPEd, n. 30, p. 21-35, set./dez. 2005 (Número especial sobre os 40 anos da pós-graduação em educação no Brasil). 
FÁVERO, Osmar. Reavaliando as avaliações da CAPES. In: A avaliação da pós-graduação em debate. Rio de Janeiro: ANPEd, set. 1999. p. 5-27. (Documentos ANPEd).

FERRARO, Alceu Ravanello. A ANPEd, a pós-graduação, a pesquisa e a veiculação da produção intelectual na área de educação. Revista Brasileira de Educação, Rio de Janeiro: ANPEd, n. 30, p. 47-69, set./dez. 2005 (Número especial sobre os 40 anos da pós-graduação em educação no Brasil).

FÓRUM NACIONAL EM DEFESA DA ESCOLA PÚBLICA. Declaração de princípios e finalidades. Brasília, 21 ago. 2001.

GATTI, Bernardete A. Formar professores ou pesquisadores no mestrado em educação? Boletim ANPEd, Rio de Janeiro: ANPEd, v. 9, n. 1, p. 31-34, jan./mar. 1987a.

A retrospectiva da pesquisa educacional no Brasil Revista Brasileira de Estudos Pedagógicos, v. 68, n. 159, p. 279-288, maio/ago. $1987 \mathrm{~b}$.

Formação de grupos e redes de intercâmbio em pesquisa educacional: dialogia e qualidade. Revista Brasileira de Educação, Rio de Janeiro: ANPEd, n. 30, p. 124-132, set./ dez. 2005 (Número especial sobre os 40 anos da pós-graduação em educação no Brasil).

GOUVEIA, Aparecida Joly. A pesquisa educacional no Brasil. Cadernos de Pesquisa, São Paulo: Fundação Carlos Chagas, v. 1, n. 1, p. 1-22, jul. 1971.

GRZYBOWSKI, Cândido. Formar pesquisadores pesquisando: alguns desafios para a pós-graduação em educação. Boletim ANPEd, Rio de Janeiro: ANPEd, v. 9, n. 1, p. 34-38, jan./mar. 1987.

HORTA, José Silvério Baía; MORAES, Maria Célia Marcondes de. O sistema CAPES de avaliação da pós-graduação: da área de educação à grande área de ciências humanas. Revista Brasileira de Educação, Rio de Janeiro: ANPEd, n. 30, p. 96-116, set./dez. 2005 (Número especial sobre os 40 anos da pós-graduação em educação no Brasil).

KUEnZER, Acácia Zeneida; MORAES, Maria Célia Marcondes. Temas e tramas na pós-graduação em educação. Educação \& Sociedade, Campinas, v. 26, n. 93, p. 1.341-1.363, set./dez. 2005.

NICOLATO, Maria Auxiliadora. A caminho da Lei n. 5.540/ 68: a participação de diferentes atores na definição da Reforma Universitária. 1986. Dissertação (Mestrado em Educação) - Fa- culdade de Educação, Universidade Federal de Minas Gerais, Belo Horizonte, 1986. 2 v.

OLIVEIRA, Betty Antunes. Estado autoritário brasileiro e ensino superior. São Paulo: Cortez; Campinas: Autores Associados, 1980.

ORTEGA, Cristina; FÁVERO, Osmar; GARCIA, Walter. Análise dos periódicos brasileiros de educação. Revista Brasileira de Estudos Pedagógicos, v. 79, n. 193, p. 161-195, set./dez. 1998.

PAOLI, Niuvenius J. Para repensar a universidade e a pósgraduação. Campinas: Ed. da UNICAMP, 1985.

RAMALHO, Betania Leite; MADEIRA, Vicente de Paulo Carvalho. A pós-graduação em educação no Norte e no Nordeste: desafios, avanços e perspectivas. Revista Brasileira de Educação, n. 30, p. 70-81, set./dez. 2005 (Número especial sobre os 40 anos da pós-graduação em educação no Brasil).

SAVIANI, Dermeval. O protagonismo do professor Joel Martins na pós-graduação. Revista Brasileira de Educação, Rio de Janeiro: ANPEd, n. 30, p. 21-35, set./dez. 2005 (Número especial sobre os 40 anos da pós-graduação em educação no Brasil). A pós-graduação em educação no Brasil: pensando o problema da orientação. In: BIANCHETTI, Lucídio; MACHADO, Ana Maria Netto (Orgs.). A bússola do escrever: desafios e estratégias na orientação e escrita de teses e dissertações. 2. ed. São Paulo: Cortez; Florianópolis: Editora da UFSC, 2006. p. 135-163.

SGUISSARDI, Valdemar. A avaliação defensiva no "modelo CAPES de avaliação" - É possível conciliar avaliação educativa com processos de regulação e controle do Estado? Perspectiva, Florianópolis: CED/UFSC, v. 24, n. 1, p. 49-88, jan/jun. 2006.

SILVA, Antonio Ozaí. A corrida pelo Lattes. In: RAMPINELLI, Waldir José; ALVIM, Valdir; RODRIGUES, Gilmar (Orgs.). Universidade: a democracia ameaçada. São Paulo: Xamã, 2005. p. 87-96.

SOUSA, Sandra Zákia. Avaliação da aprendizagem: natureza e contribuições da pesquisa no Brasil, no período de 1980 a 1990. 1994. Tese (Doutorado em Educação) - Faculdade de Educação, Universidade de São Paulo, São Paulo, 1994.

WATERS, Lindsay. Inimigos da esperança: publicar, perecer e o eclipse da erudição. São Paulo: Editora da UNESP, 2006. 


\section{Referências sobre os vínculos institucionais dos participantes com a ANPEd}

ALCEU RAVANELLO FERRARO, presidente da ANPEd (19891993), membro das Comissões de Avaliação da CAPES (19821986), do Comitê Científico da ANPEd (1994-1995) e do Comitê Assessor de Educação do CNPq (1997-1998).

BERNARDETE A. GATTI, sócia da ANPEd desde o final dos anos de 1970; no início dos anos de 1980 representou a associação na Coordenação de Educação e Cultura do CNPq e no Grupo Coordenador do Programa Integrado de Educação do CNPq, em cooperação com a FINEP e o INEP. Foi membro do Comitê Assessor de Educação do CNPq de 1984 a 1987, e coordenadora da área de educação junto à CAPES de 1989 a 1992. Desde 2003 até a presente data integra a Diretoria da ANPEd, como membro do Conselho Fiscal.

CARLOS ROBERTO JAMIL CURY foi presidente da Comissão de Consultores da área de educação junto à CAPES nos períodos 1984-1986 e 1996-1998; coordenou o trabalho Avaliação e perspectivas na área de educação 1983-1991 (convênio CNPq/ANPEd, em 1991/1992); foi membro do CNE de 1996 a 2004, tendo assumido a presidência da Câmara de Educação Básica, e presidente da CAPES em 2003.
JACQUES THERRIEN integra a associação como sócio desde a reunião em Fortaleza (1978), tendo sido coordenador do grupo de trabalho Educação Rural (1987) e desse mesmo grupo transformado em Educação e Movimentos Sociais no Campo (1988-1990). Coordenou o FORPRED (1993-1995) e é membro do Conselho Fiscal (2005-2007). Participou da Comissão de Avaliação da CAPES (em 1998 e 2007) e do Comitê Assessor do CNPq (19982001).

LUCÍDIO BIANCHETTI foi vice-presidente da ANPEd no biênio 2003-2005, e desde 2003 é participante da Comissão Editorial da Revista Brasileira de Educação.

MARIA MALTA CAMPOS foi coordenadora do grupo de trabalho Educação de Crianças de 0 a 6 anos, vice-presidente da ANPEd no biênio 1993-1995 e presidente nos biênios 1995-1997 e 1997-1999, quando foi também editora responsável da Revista Brasileira de Educação. Participou do Comitê Assessor de Educação do CNPq no período 1989-1991, tendo sido sua coordenadora em 1990-1991. Participou do Comitê Científico da ANPEd em 1993-1995.

SANDRA ZÁKIA SOUSA é atualmente vice-presidente da ANPEd, biênio 2006-2008, e participante da Comissão Editorial da Revista Brasileira de Educação desde 2006.

VALÉRIA LOPES, doutoranda em educação na USP, foi assessora do debate. 


\section{Resumos/Abstracts/Resumens}

Sandra Zákia Sousa e Lucídio Bianchetti

Pós-graduação e pesquisa em educação no Brasil: o protagonismo da ANPEd

Resultante de debate ocorrido, em maio de 2007, entre sócios da ANPEd com atuação destacada na criação, organização, gestão e nos rumos da associação, o artigo apresenta, a partir de uma retrospectiva histórica, algumas visões acerca do movimento da pósgraduação e da pesquisa em educação no Brasil. A ênfase recai nos encaminhamentos assumidos pela ANPEd, a partir de aspectos relacionados a sua organização interna, bem como a sua articulação com órgãos governamentais, grupos da sociedade civil e outras associações acadêmicas e científicas. Além dos resgates, a análise apresenta perspectivas para a consolidação e ampliação de iniciativas da ANPEd, no sentido de fortalecer sua atuação como indutora da melhoria da qualidade da pesquisa e da formação pós-graduada.
Em especial, destaca o protagonismo da associação, como interlocutora na formulação e implementação de políticas públicas de educação.

Palavras-chave: ANPEd; pós-graduação em educação; formação e pesquisa

Postgraduate studies and research in education in Brazil: the ANPEd's leading role

As a result of the debate which took place in May 2007 between members of ANPEd with a distinguished role in the creation, organization,

administration and direction of the association, this article presents some considerations on the movement of postgraduate studies and research in education in Brazil, based on an historical retrospective. Emphasis is given to the procedures adopted by ANPEd, based on aspects related to its internal organization, as well as its articulation with governmental organs, civil society groups and other academic and scientific associations. In addition to the task of historical recovery, the analysis presents perspectives for the consolidation and amplification of the association's initiatives, with a view to strengthen its inductive role in the improvement of the quality of research and postgraduate training. It highlights especially the Association's leading role as interlocutor in the formulation and implementation of public policy in education.

Key words: ANPEd; postgraduate studies in education; training and research

Postgrado y pesquisa en educación en Brasil: el protagonismo de la

\section{ANPEd}

Resultante del debate ocurrido, en mayo del 2007, entre socios de la ANPEd con actuación destacada en la creación, organización, gestión y en los rumbos de la asociación, el artículo presenta, a partir de una retrospectiva histórica, algunas visiones a respecto del movimiento de postgrado y de la pesquisa en educación en Brasil. El énfasis recae en los encaminamientos asumidos por 
la ANPEd, a partir de aspectos relacionados a su organización interna, bien como a su articulación con los órganos gubernamentales, grupos de la sociedad civil y otras asociaciones académicas y cientificas. Además de los rescates, el análisis presenta perspectivas para la consolidación y ampliación de iniciativas de la ANPEd, en el sentido de fortalecer su actuación como inductora de la mejoría de la calidad de la pesquisa y de la formación del postgrado. En especial, destaca el protagonismo de la asociación, como interlocutora en la formulación e implementación de políticas públicas de educación.

Palabras claves: ANPEd; postgrado en educación; formación y pesquisa 